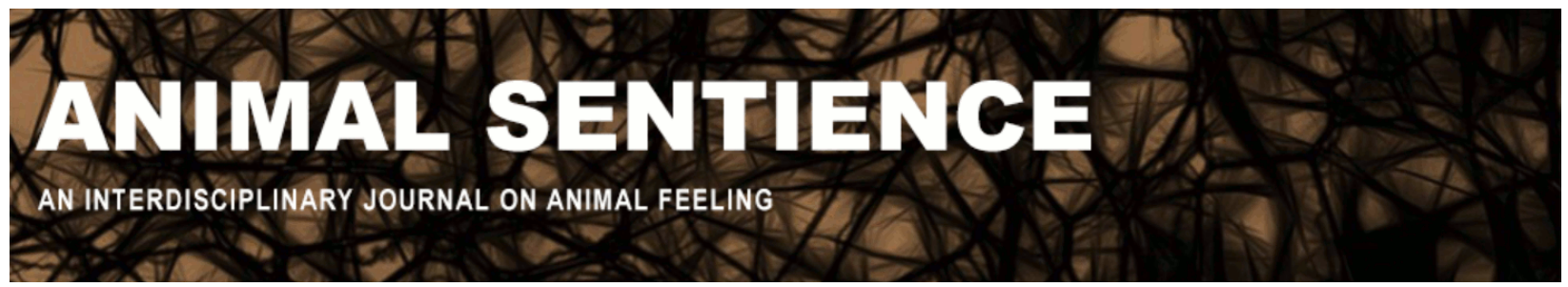

Kiley-Worthington, Marthe (2016) Nonhuman mind-reading ability. Animal Sentience 1(2)

DOI: $10.51291 / 2377-7478.1083$

Date of submission: 2016-01-23

Date of acceptance: 2016-01-25

(c)

This article has appeared in the journal Animal

Sentience, a peer-reviewed journal on animal

cognition and feeling. It has been made open access,

free for all, by WellBeing International and deposited

in the WBI Studies Repository. For more information,

please contact

wbisr-info@wellbeingintl.org.

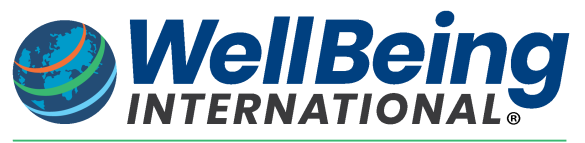

SOLUTIONS FOR PEOPLE, ANIMALS AND ENVIRONMENT 


\title{
Nonhuman mind-reading ability
}

Commentary on Harnad on Other Minds

\author{
Marthe Kiley-Worthington \\ Centre d'Eco-Etho Recherche et Education \\ La Drome, France
}

\begin{abstract}
Harnad (2016) is mistaken that humans are better at mind-reading than other species. Humans have context-independent language, but nonhuman species, especially mammals, have context-dependent nonverbal skills - perceptual, communicative and social - that can be much keener than our own.
\end{abstract}

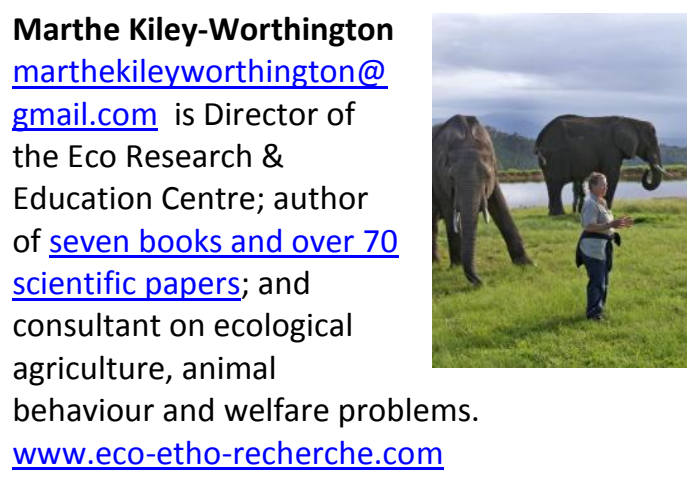

Although I am in agreement with much of Harnad's argument, as an ethologist who has studied mammal behaviour most of my life both scientifically and professionally (keeping and teaching mammals), an animal welfare scientist, and an amateur philosopher, I would like to take issue with several of his statements and perhaps take the debate a step further in our consideration of other species.

In the first place, despite being sympathetic to nonhumans, Harnad still seems to make a "them" and "us" distinction. Thus, he appears to endorse the current belief in the superiority of all humans' mental skills. Many who deal with animals on a daily basis are not so sure about this. It may be that the main reason animals enrich some of our lives (apart from working for us in many ways) is that they have different mental skills that open up new worlds - not just because they feel, nor because they have some mental skills similar to ours (but they are not so good at them as we are). They are not preverbal children or mentally handicapped humans who cannot talk; nor are they controlled by "instinct." That individual other mammal has similarities to us and differences from us, just as we have with one another. Some have greater mental abilities in some respects than I or Harnad (however great his human intellectual abilities!)

The first step in this endeavour is to recognize our emotions (which is what this journal is doing). But, in addition, there are also our behavioural and other mental similarities (e.g., how we learn and acquire knowledge, and the flexibility of our behaviours). If we are mammals, then evolutionary continuity indicates that we share characters with close relatives. In the study of behavioural and mental attributes, this is often ignored. The second 
step is to study carefully the species' morphology, anatomy, physiology, neurophysiology, and behaviour, and to ponder some questions in the philosophy of mind in the attempt to understand the subjectivity of that species or individual.

It is this different take on the world that opens new worlds for some of us, and leads us to reconsider how and with whom we live, not only because they feel, have emotions and are conscious, or because of ecological concerns for conserving species for future generations, or because we must be compassionate and empathetic, or because they have a brain that works more or less like ours, or because of economics or the law (as argued, for example, by Ng 2016 and Lachance 2016).

The central reason for having nonhuman animals around, and living with them if we wish to, is that they have minds that matter to us. Part of my private world (which, like others, I try to communicate to other humans, not always successfully) is the endeavour to discover something more about their world (and not only about their emotions) by studying them and also by living closely with them.

Because many scientists and philosophers lack knowledge of the emotional beings they discuss or study, and believe that critical or conditional anthropomorphism is unimportant, the "we/they" distinction remains uppermost in their minds, and consequently in their observations and understanding. For example, just as all mammals have feelings and emotions, they are capable of social learning by imitation (Avital \& Jablonka 2000), perhaps by means of "mirror neurons" (Cook et al. 2014); they can communicate with others and have "social contracts" (Redhead \& Dunbar 2012). To do all this they must be able to "mindread" (Krebs \& Dawkins 1984); they must have a "theory of mind" (Premack \& Woddruff 1978). In fact, the mammals I know can mind read rather better than can I, a fairly normal human female (Kiley-Worthington 2000).

The statement that Harnad makes that surprises me is that nonhuman animals' ability to mind-read is inferior to ours. I looked up "mind reading" in Wikipedia to find what he may mean by this, but I don't think he means what it says.

Perhaps what Harnad means is that mind-reading is the ability of one human to interpret the behavior of another and to understand how that other is feeling and what his next action might be. Humans talk about their feelings and their intentions in context-independent language where what they are talking about need not be present or observed. Not having such a language does not mean that the individual is not feeling, thinking or conscious. Having and using a context dependent language or communication system - which ungulates, canids and felids have - requires a great deal more mind-reading and awareness of others and their minds (intentions) by observation than a context-independent language does. All social living requires some rules (a social contract) for a society of mammals (at least) to operate. Individuals must perceive what others feel and what they may do next otherwise this type of society cannot operate. To remain in the society, members need to mind-read and be aware that others have minds and desires and can make choices. All mammals are social, although a few species are social only with their mothers when they are young or when finding mates and desiring sex, when mind-reading is especially important! 
That other mental aptitudes exist and are perhaps of considerable interest is beginning to be understood from studies on the abilities of some autistic or other "mentally handicapped" humans (e.g., Håkansson \& Westander 2013). Normal humans think in language, with its strengths (symbols, written language, mathematics, the internet, etc.) and weaknesses (lack of consideration of feelings in science and other intellectual pursuits, and an inability to observe or think other than in human linguistic terms). This limits human comprehension of the world to that of human language, and its particular mental attachments.

Most mammals practice context-dependent communication. This means that a vocalization or another behaviour (such as tail wagging, head throwing, rushing about) tells the recipient about the general level of arousal or excitement of the communicant: his general emotional state. The reason the individual is aroused or excited comes from the contextual cues, what is going on socially and environmentally. So the same call or other behaviour means different things depending on the context (Kiley-Worthington 1972); for example, it may signal being frightened, aggressive, sexy, happy, etc.

Many nonhuman mammals are in fact very much better at mind-reading than I am. When one is free-contact teaching a very large animal that could easily kill you if he is annoyed (such as an elephant or a Cape buffalo), it is important to be very aware of what he is thinking or feeling about you, and what you are thinking about him. It is not easy to read his mind, at least until one is very familiar with the individual; but generally the animal one is teaching has very little difficulty, even when he does not know humans at all, in reading my intentions and feelings, although he may struggle to understand my spoken language, at least to start with. Those species I know best - ungulates (horses, cattle, buffalo, elephants, sheep, goats pigs, antelopes, deer, rhino, small camelids), some felids (tigers, lions and domestic cats), and some canids (domestic dogs of many breeds, jackals) - read my intentions by closely observing me and by reading a host of contextual cues. Even naïve individuals (recently caught from the wild) are able to read my intentions: whether and when am I going to approach; where, how, if and what I am going to do next; and whether I am excited or not, and if so, why. The first clues on general arousal state come from postural tonus, muscular tension or relaxation, facial expression, direction of gaze, and possibly vocalisations. Clues as to my particular emotional state - frightened, happy, aggressive, sexy, uncertain, and so on - come from the context, the social situation (which other individuals are around and what are they doing). The nonsocial environment gives further clues for the interpretation of my behavior, feelings and intentions. The subject then chooses what to do, as a result of this information.

If I am frightened, the other mammal is likely to be frightened too, by reading my tenseness and fear, and consequently he may try to run away, or attack out of defensive threat. Consequently, how you behave when trying to approach another is crucial to how he will behave. If you are told before you approach a horse "careful, that one bites," you are much more likely to be bitten than if you have no information, because you predict it and show it in your body: He has read your mind and feelings (evidence for this comes from many videos and from animal-handlers and teachers).

Trying not to show what you feel (in other words lying) usually does not work because the animal is capable of reading your fear, even though you appear relaxed to another human. 
Nonhumans often read slight visual, muscular or postural cues that another human finds very difficult to detect. A well-known example is Clever Hans, the horse who managed to read the audience's responses and solve simple mathematical problems: That was mindreading - and he taught himself to do it (Heinzen et al. 2015)!

Sometimes, too, the animal will learn to manipulate you by behaving in certain ways, (e.g., a dog sighing and groaning because he has not had his walk that day). He can change your area of attention by looking away from something so that you look that way too; he can "lie" (Searcy \& Novicki 2005) - pretending that he is stiff and cannot move when he does not want to, again "mind-reading."

When another mammal fails to learn to do something when taught, it is generally because he has "mind-read" the teacher but the teacher has not mind-read him, and has hence made teaching mistakes (Kiley-Worthington \& Rendle-Worthington 2012). When the animal has learned to keep doing the wrong thing, this is very often (about $85 \%$ of cases in my practice as a behavioural consultant) because of the teacher's inability to mind-read the animal together with the animal's ability to mind-read the teacher: The animals realize how they can avoid doing something because of that teacher's inability; they invent an undesired behavior, and because it achieves their desired goal, they learn to keep doing it. Of course, they can, with care, like a human, be taught not to keep doing it too!

If we take into account the innate tendencies of the species as well as their past experiences, (that is, what they have learnt during their lives, their knowledge), if we recognize our commonalities as well as our real differences in mind and body, we will begin to understand how another species or individual feels or thinks, and what mental aptitudes they have. This is a "conditional anthropomorphic" approach (Burghardt 1991; 2016). It involves a multidiscipline effort to better understand the subjectivity and epistemology of the other species or individual (Kiley-Worthington 2000; 2005). The recognition of this different world view can enrich our own; we humans can then see the world differently and recognize our own mental inabilities, even though we may not have it all exactly right from the other's point of view.

Harnad is right: It is our common sentience that joins us. But we must not ignore our shared mental abilities. The latter may be more useful in convincing the anthropocentric intellectual to respect others more! The second step is to study some of our differences, to learn more about our own mental shortcomings, and not assume that other species are unable to do what we can do because we possess and depend on human language! Let us begin to do this before we irredeemably lose different world views as species become extinct. 
Harnad Response: I defer completely (and with great admiration) to Marthe Kiley-Worthington's own superhuman other-mind-reading powers, including all the remarkable things she discerns with them and reports here and elsewhere about the other-mind-reading powers of nonhuman species.

In many respects, other mammals are clearly far better mind-readers than we are. The reason I nevertheless insisted that we were the better mind-readers overall is precisely what Kiley-Worthington refers to as "context-independent language" (including its systematic use in the scientific study of animal behaviour, cognition and sentience, as reported, for example, in this journal).

Ours is the only species that can observe and communicate all the things that Kiley-Worthington explains to us (in words) about animals' behaviour and their mind-reading ability (including their admirable and touching capacity to manipulate and mislead us!). That - and the capacity to infer that when Professor P said X he must have been assuming that Professor Q meant Y.

That infinite universe of potential propositions - about anything at all - that humans can have in mind, and can infer that others have in mind, or, failing that, can state verbally ("mind-writing"!), so that we can "read" exactly what they had in mind: that's what other species lack. And that's what makes us, formally speaking, the mind-reading champions overall.

I don't doubt that it is the lack of a "context-independent language" that prevents any other species from exploiting the planet as successfully and as disastrously as our own species has done, decimating or subjugating all its other species.

But is it not our species' relatively inferior nonverbal mind-reading capacity, as extended by our unique capacity for "context-independent language," that allows us to come to know the agony that we are inflicting on other minds as no other species could, and also holds out the hope that we can see our way to remedying it, legally and culturally, as we have done with our other abominations, such as genocide, slavery, torture, rape and racism?

\section{References}

Avital, E., \& Jablonka, E. (2000). Animal traditions, behavioural inheritance in evolution. OUP.

Burghardt, G. (1991). Cognitive ethology and critical anthropomorphism: A snake with two heads and hog-nosed snakes that play dead. In C. A. Ristau (Ed.), Cognitive ethology. Erlbaum, Hillsdale.

Burghardt, G. (2016). Mediating claims through critical anthropomorphism. Animal Sentience 2016.024 . 
Cook, R., Bird, G., Catmur, C., Press, C., \& Heyes, C. (2014). Mirror neurons: From origin to function. Behavioral and Brain Sciences 37: 177-192.

Hakansson G., \& Westander, J. (2013). Communication in humans and other animals (p. 62). John Benjamin.

Harnad, S. (2016). Animal sentience: The other-minds problem. Animal Sentience 2016.001.

Heinzen, T. E., Lilienfeld, S. O., \& Nolan, S. A. (2015). Clever Hans: What a horse can teach us about self deception. Skeptic 20(1): 10-18.

Kiley-Worthington, M. (2000). Equine and elephant epistemology, Right in front of your mind. M. Phil thesis, University of Lancaster, UK.

Kiley-Worthington, M. (2005). Horse watch. What is it to be a horse? J. A. Allen.

Kiley-Worthington, M., \& Rendle-Worthington, J. (2012). Exploding the myths: Large mammal handling and teaching. London: Ex Libris.

Krebs, J. R., \& Dawkins, R. (1984). Animal signals: Mind-reading and manipulation. In J.

R. Krebs \& N.B. Davies (Eds.), Behavioural ecology: An evolutionary approach. Wiley.

Lachance, M. (2016). Breaking the silence: The veterinarian's duty to report. Animal Sentience 2016.006.

$\mathrm{Ng}$, Y-K. (2016). How welfare biology and commonsense may help to reduce animal suffering. Animal Sentience 2016.007.

Premack, D., \& Woodruff, G. (1978). Does the chimpanzee have a theory of mind?. Behavioral and Brain Sciences 1: 515-526.

Redhead, G., \& Dunbar, R. I. (2012). The functions of language: An experimental study. Evolutionary Psychology 11(4): 845-854.

Searcy, W. A., \& Nowicki, S. (2005). The evolution of animal communication: Reliability and deception in signaling systems. Princeton University Press. 